\title{
TRAVEL TIME USE IN THE INFORMATION AGE
}

\author{
Glenn Lyons \\ Centre for Transport \& Society, University of the West of England, Bristol, UK
}

John Urry

Centre for Mobilities Research, Sociology Department, Lancaster University, UK

\begin{abstract}
This paper, focused primarily on UK data and debates, considers the potential significance of travel time use within past, present and future patterns of mobility. In transport scheme appraisal, savings in travel time typically represent a substantial proportion of the benefits of a scheme - benefits used to justify its often enormous financial costs. Such benefits are founded on the assumption that travel time is unproductive, wasted time in-between 'real' activities and which should be minimised. Travel demand analysis treats travel time and activity time as separate, albeit acknowledging an interdependency.

The paper challenges these approaches by exploring how travel time can be, and is, being used 'productively' as activity time, and what enhancements to time use might be emerging in the 'information age'.

Such undermining of the division between activities and travelling, and between activity time and travel time, may have major implications for future levels of mobility, for the modal distribution of travel, for the validity of current transport appraisal methodology and for the analysis of travelling within the information age. These issues are considered.
\end{abstract}




\section{INTRODUCTION}

Personal travel across modes in Great Britain $(\mathrm{GB})^{1}$, when measured in billion passenger kilometres, increased from 218 in 1952 to 728 in 1999 with an increase in the last decade alone of some 7 per cent (DETR, 2001a). Between 1972 and 2000 the average annual distance travelled per person in GB increased by 53 per cent. Over the same period the average number of trips increased by only 8 per cent and the time spent making these trips increased by only 2 per cent (DTLR, 2001). The average time spent travelling has remained at around one hour per person per day for the past three decades. Increases in journey speed (achieved by improvements in vehicle performance, a willingness to drive vehicles faster, changing modes, departure times or routes, or because of improvements to the transport system) are responsible for enabling people to travel further - increasing their spatial range of access to people, goods, services and opportunities. The Government's stated vision is “for journeys that are quicker and more convenient by making it easier to switch between different forms of transport” (DETR, 2000a).

From this brief overview it would appear that the future of mobility in the UK (and other countries), in conjunction with the endeavours of current transport policies, is set to see the pursuit of access spread over ever increasing distances. Where this is not being facilitated by measures to improve the capacity and efficient operation of the road network, it is being supported and perhaps encouraged by substantial investment in the capacity and performance of other modes, notably rail and air. If mobility is set to continue increasing, questions must be raised as to whether or not this is desirable.

Economically, transport connects people to opportunities and hence yields positive benefits. Yet journey time itself is judged in economic terms as wasted time and hence counters the utility of accessing opportunities. In this context alone, the net benefit can be increased if journey times are reduced while maintaining the level of access. This can be achieved either by moving the opportunities closer to the people or by moving the people more quickly to the opportunities. There are also environmental and social consequences of mobility to consider. In terms of the social

\footnotetext{
${ }^{1}$ Great Britain (GB) is comprised of England, Wales and Scotland. The United Kingdom (UK) is comprised of Great Britain and Northern Ireland. Within this paper, in some cases national statistics apply only to GB. Otherwise reference will be made to the UK.
} 
consequences of increasing mobility, Adams suggests that making reference to increases in the distance the average person travels masks a growing disparity amongst the population (Adams, 1999). Those who lie below the average may not be able to afford higher levels of mobility. Their spatial range of access may be constrained by mobility afforded by walking, cycling and public transport (see Cass, Shove, Urry 2003; Raje, 2003, on the gender and ethnic implications). This extent of access is being eroded by changes in land use patterns that arise from those above the average having greater spatial ranges, afforded notably by car use (but see Froud, Johal, Leaver, Williams, 2003, on the 'motoring poor'). A typical illustration of this is the disappearance of local shops and amenities resulting from larger and more financially successful 'centralised' substitutes that are often further away, with a dependence on the car for access. The quality of local existence is therefore reduced. Those able to afford mobility can overcome this problem unlike those who cannot who then suffer from mobility-related social exclusion (Kenyon et al, 2002).

In this paper we focus upon a key feature of the preceding commentary and arguably one of the most crucial factors that has shaped and will continue to shape the nature of mobility and development of our land use and transport systems, namely travel time or more specifically the amount, value and use of travel time.

We begin by outlining some established conventions relating to travel time, namely that: (i) the amount of daily travel time per person remains stable; (ii) in economic terms time spent travelling is unproductive and wasted; and (iii) activity time and travel time are mutually exclusive. We then articulate an hypothesis that challenges these conventions. The paper goes on to elaborate on understandings that relate to this hypothesis and in some respects, though not conclusively, tend to support it. Lastly we discuss what considerations should come to bear on the hypothesis in terms of its validity and implications.

\section{ESTABLISHED CONVENTIONS}

\section{Travel time budget}

It is claimed that: "People spend somewhat more than one hour per day travelling, on average (travel time budget), despite widely differing transportation infrastructures, geographies, cultures and per 
capita income levels" (Schafer, 1998: 459). The notion that a travel time budget is stable over time and space and independent of modes of travel remains subject to much debate. Theoretical explanations of the possible constancy include: biological programming (evolution has left us biologically programmed to spend a fixed amount of time on travel); utility maximisation (an optimum point is reached that reconciles increased travel time to access a larger supply of activities with reduction in time to undertake such activities caused by increased travel times); and social routine (everyday life is full of settled routines of which travel becomes a part and takes its share of the allocation of time between all parts of the routine) (Höjer and Mattson (2000). The notion itself was recognised at least as far back as the 1970s and much empirical work seeks to confirm the phenomenon (see Mokhtarian and Chen, 2004, for an extensive review). The appeal of a fixed travel time budget is that it can aid the accuracy of projections of future (total) mobility and the share taken by each mode. Moreover, if a limit to journey speed can be reached or can be enforced, then it suggests that total mobility (in terms of distance travelled) within a given society might eventually plateau - something which, whilst not necessarily positive in economic terms, would intuitively appear a desirable future state with regard to environmental and social considerations.

However, it is clear that the constancy of such a travel time budget only at best applies at the aggregate level. Höjer and Mattson (2000) caution against the danger of generalising, i.e. claiming the validity of the argument for people in general. There is a tendency to deduce a general law from an average and then to imply that the average becomes the norm. Once behaviour is disaggregated then large variations become apparent. For example, Londoners spend 30 per cent more time travelling than those living in Scotland (Schafer and Victor 2000: 174). An alternative hypothesis has thus been offered by Mokhtarian and Salomon who argue: "Rather than uniformly trying to minimise travel, people seek to decrease their travel if it exceeds the desired optimum, but seek to increase travel if it falls short of their ideal amount” (2001: 712).

\section{Transport appraisal and the value of time}

Transport system interventions are typically intentional changes to transport supply, i.e. the capacity, availability and usage cost of the transport network. Historically, interventions have most commonly 
concerned the building of new infrastructure, notably new highway. Before a decision is taken to proceed with an intervention, the proposed intervention must be appraised. In the UK in 1998 the then Department for the Environment, Transport and the Regions (DETR) developed the New Approach to Appraisal (NATA - DETR, 1998). The purpose of NATA is to provide advice on prioritising and choosing between different options for solving the same problem. Appraisal is centred upon the five objectives of environment, safety, economy, accessibility and integration. It is largely based on two key components - the Cost Benefit Analysis (CBA) and the Environmental Impact Assessment (EIA).

In appraisal, calculation of transport user (dis)benefits is based on (DETR, 2000b):

- changes in travel time;

- changes in user charges, including fares, tariffs and tolls; and

- changes in vehicle operating costs met by the user.

In an investigation into links between transport and the economy it was importantly noted that "Travel time savings are the single most important component in the measured transport benefits/disbenefits of most schemes and policies. Hence the methods of valuing them critically affect the measurement of the economic impacts of schemes” (DETR, 1999: 183).

In appraisal it is assumed that "time spent travelling during the working day is a cost to the employer's business. It is assumed that savings in travel time convert non-productive time to productive use and that, in a free labour market, the value of an individual's working time to the economy is reflected in the wage rate paid." (DETR, 2000b). Government "Guidance on the Methodology for Multi-Modal Studies’ (GOMMMS) further notes that "changes in travel time on employer's business are valued the same whatever the stage of the journey is involved, i.e. there is no weighting applied to take account of the reluctance of passengers to walk to/from or wait for transport services. This is because the time spent or saved is assumed to be lost or gained in productive working time - the travel activity taking up the time is therefore deemed irrelevant.” (DETR, 2000b). Values of time disaggregated by modal group are used in appraisal and are based on National Travel Survey data on the incomes of working travellers on each mode.

For non-working time (taken to include travelling to and from work) values instead reflect people's willingness to trade time for money. Values are determined from revealed and stated 
preference studies of which there have been many (Wardman and Mackie, 1997). Willingness to pay will depend on a number of factors such as the traveller's income, the value and urgency attached to the journey purpose and the comfort and attractiveness of the journey. However, to avoid significant equity implications, and notably a bias towards measures which benefit travellers with higher incomes, a standard 'national average' value is used in appraisal. Unlike valuation of travel time during work, for non-work journeys "waiting for public transport and all walking and cycling (whether in connection with a journey by a motorised mode or not) should adopt a value which is double the standard in-vehicle value” (DETR, 2000b). (In 2004, the UK Department for Transport (DfT) accepted a recommendation to increase wait time values (but not walk time values) to two and a half times the in-vehicle time (DfT, 2004).) The majority of journeys take place in non-working time and consequently "time savings to travellers in their own time typically make up a large proportion of the benefits of transport investment” (DETR, 2000b).

Table 1: Values of Time per Person (£/hour, 2002 prices and values) (DfT, 2004)

\begin{tabular}{lr}
\hline & $\begin{array}{r}\text { Resource } \\
\text { Cost (£/hour) }\end{array}$ \\
\hline Working Time: & \\
car driver & 21.86 \\
car passenger & 15.66 \\
PSV (bus) passenger & 16.72 \\
taxi passenger & 36.97 \\
rail passenger & 30.57 \\
underground passenger & 29.74 \\
walker & 24.51 \\
cyclist & 14.06 \\
motorcyclist & 19.78 \\
\hline Non-Working Time: & \\
commuting & 4.17 \\
other & 3.68 \\
\hline
\end{tabular}

This approach to the treatment of the valuation of travel time in appraisal "has been the practice in the UK since the earliest transport cost benefit analyses in the 1960s” (DETR, 1999). The latest values of time are shown in Table 1. As a reminder, the working time costs are based on the assumption that travel time is wasted. The costs reflect the 'average' type of passenger using each mode and not the 
mode itself (or rather its attributes). Consideration will be given to the values in Table 1 later in this paper.

Values of time are addressed in both modelling and appraisal. Behavioural values are used in the modelling process to ensure that people's perceptions are correctly represented (DETR, 1999). The modelling process establishes the patterns of travel, by mode, that take place. Such patterns are influenced by responses from travellers to changes in the 'cost' of travel. In turn vehicle or passenger flows estimated by the modelling are used in the economic appraisal of scheme options.

A significant piece of work for the DfT was reported on in 2003 which sought to "review the evidence on the valuation of work and non-work travel time savings” (Mackie et al, 2003). In addressing travel time in employers' business, the report considers an approach to valuation of time savings proposed by Hensher (1977). This approach, at least conceptually, attempts to account for the following: the proportion of travel time saved at the expense of work done while travelling (p); the productivity of work done while travelling relative to at the workplace (q); and the proportion of travel time saved used for leisure (r). Mackie et al consider two types of travellers for travel time in employers' business - those whose travel is an integral part of their jobs (e.g. service engineers, delivery people, public transport drivers) and employees travelling in the course of business (termed 'briefcase travellers').

Recommendations made by the report concerning values of time for use in modelling and appraisal were informed by three sets of consideration, namely: evidence; policy; and practicality. The expressed view is that "the Hensher formula approach is data hungry, and that none of the various parameters, r, p and q are at all easy to estimate with confidence” (Mackie et al, 2003: 13). Mackie et al believe that on balance (given the continual improvement in vehicle quality and available facilities) "changes in the disutility of travel will operate to reduce the value of time over time" (Mackie et al, 2003: 50). They go further in recognising that the "the opportunity to use travel time productively can be expected to impact on the value of time, and in this respect the advent and widespread ownership and use of mobile phones and the possibility to use laptop computers on some made may have had a significant downward influence on the value of time. Future developments may further increase the quality and quantity of useful activities which can be undertaken while travelling.” (Mackie et al, 
2003: 50). Conversely they expect income growth to lead to increases in the value of travel time savings.

In spite of the above recognition of the use of travel time and its (increasing) future significance (an issue central to this paper), the report's recommendation is that for the time being appraisal should continue with its current treatment of time as unproductive. It appears that the report is simultaneously acknowledging a shortcoming in this current treatment while arguing that to change the assumptions in appraisal without being able to have a suitable evidential basis for doing so would be inappropriate. In 2004 the DfT accepted most of the report's recommendations (DfT, 2004) and so at the time of writing, travel time in the UK is presumed, in economic terms at least, to be wasted, unproductive time.

\section{Travel time and activity time}

The treatment of travel time in UK appraisal straightforwardly identifies travel as wasted time and (implicitly) as discrete from the activities undertaken which give rise to travel. Traditionally, modelling approaches, whilst able to incorporate some differences in the behavioural valuation of time, treat the time spent travelling in isolation from time spent undertaking activities. In other words a trip-based approach is adopted. However, more than 20 years ago the alternative activity-based approach was developed, based on the idea that travel demand arises, or is derived, from the desire or need to participate in activities. "T[t]he development of the activity-based approach to travel demand analysis is characterised by a desire to understand the phenomenon of urban travel, not merely to develop predictive models that appear to produce acceptable forecasts” (Pas, 1996). The activitybased approach acknowledges that daily patterns of travel are shaped around, and dictated by, the concurrent planning of activity schedules. Nevertheless, this approach too treats travel time and activity time as separate notions, albeit with some assumed interdependencies.

In a rare example of travel time and activity time being considered together, Schwanen and Dijst examine the relationship between travel time and activity duration, or more specifically the relationship between commuting time and work duration (based on the 1998 Dutch National Travel Survey: Schwanen and Dijst, 2002). Their assumption is that individuals balance travel time and 
activity duration leading to the notion of a planned or realised travel-time ratio, defined as 'the ratio between travel time and the sum of travel time and activity duration'. Whilst an average travel-time ratio is determined from their research, variation around the average value is considerable. Table 2 shows the overall values of travel-time ratio by mode. What is noticeable is that people accept considerably higher travel-time ratios when travelling by public transport compared with travelling by car. This is an issue returned to later.

Table 2: Travel-time ratio concerning commuting time and work duration by mode (Schwanen and Dijst, 2002)

\begin{tabular}{lr}
\hline Mode of travel to/from work & Travel-time ratio \\
\hline car driver & 0.111 \\
car passenger & 0.107 \\
bus/tram/metro & 0.159 \\
train & 0.222 \\
bicycle & 0.073 \\
walking & 0.050 \\
\hline
\end{tabular}

\section{THE HYPOTHESIS}

In light of current conventions and associated issues we propose the following:

The boundaries between travel time and activity time are increasingly blurred. Specifically, many people are using travel time itself to undertake activities. The 'cost' to the individual of travel time is reduced as travel time is converted into activity time. In turn, less of the individual's travel time budget is used, enabling more travel or encouraging greater use of modes that may enable en-route activities to be undertaken.

The use of the adverb in the first sentence of the hypothesis is intended to indicate that we believe that not only are travel and activities often intertwined but also that the relationship between the two is changing. Specifically we suggest that what we term the 'information age' is equipping people in new ways to make more flexible and extensive use of their time on the move. This will be addressed later. 
In a moment we will move on to elaborate upon the use of travel time. Firstly, some brief remarks are warranted concerning reference to the travel time budget in the hypothesis. The validity or not of a constant travel time budget (at either the aggregate or individual level) is not central to the focus of the hypothesis. It is included to illustrate that productive use of travel time has the potential to overcome or extend any fixed limit imposed on an individual's or society's level of mobility. If such a fixed limit does not exist then the hypothesis still points towards the productive use of travel time enabling the level of mobility to increase even further.

\section{TRAVEL TIME USE}

Central to the hypothesis and to this paper as a whole is the contention that travel time is not (always) wasted. We consider the following set of possible time uses might exist for a journey by train:

- sleeping/snoozing

- reading for leisure

- working (reading/writing/typing/thinking)

- $\quad$ talking to other passengers

- window gazing/people watching

- playing games (electronic or otherwise)
- $\quad$ listening to music/radio

- $\quad$ text messages/phone calls - work

- $\quad$ text messages/phone calls - personal

- $\quad$ eating/drinking

- entertaining children

- $\quad$ being bored/anxious

Evidently the last of these time uses ('being bored/anxious') is unproductive. Indeed some of the other time uses could be seen to constitute 'killing time'. However, many of these time uses offer a positive value to the individual (even if not always in economic terms) serving to offset the investment of time made in the journey in order to participate in an activity at the destination (or the return journey following participation in an activity).

Consideration of travel time use in the transport studies literature is rare and only recently (in the UK at least) are social scientists turning their attention to mobility and particularly the experiences of being on the move. We now set out, firstly, a summary of some salient points within the available transport studies literature; and secondly, a sociological interpretation of being on the move. Within the latter we begin to introduce consideration of the (growing) significance of information and communication technologies (ICTs) in relation to time spent on the move. 


\section{Positive utility of travel}

Mokhtarian and Salomon provide a significant contribution to analysing travel time use (2001; and see Salomon and Mokhtarian, 1998). They suggest that positive utility is gained from one or more of three elements of a journey to a given destination: "1. the activities conducted at the destination; 2. activities that can be conducted while travelling; 3. the activity of travelling itself” (Mokhtarian and Salomon (2001: 701). The first element adheres to conventional wisdom in transport modelling and appraisal, that ideally the individual traveller would forego travelling to the destination if this were at all possible. The second element reflects the potential utility of activities that can be undertaken while on the move. Mokhtarian and Salomon note how some examples of this might be 'anti-activity' ("the ability to use the time for relaxing or thinking, including 'shifting gears' mentally between origin and destination activities and roles": 2001: 702). The third element is: “a consequence of intrinsic aspects of travel itself...the sensation of speed, movement through and exposure to the environment, the scenic beauty or other attraction of a route” (Mokhtarian and Salomon, 2001: 703; see Featherstone, Thrift, Urry, 2004, on the pleasures of speed, movement and emotion involved in car travel). Mokhtarian and Salomon argue that 'excess travel' is that resulting from the second and third elements.

Interestingly, while Mokhtarian and Salomon point to the difficulty of being able to disentangle the three elements and to identify their relative weightings, their survey showed that: "nearly half [of respondents] disagree that travel time is generally wasted time. More than a third see their commute trip as a useful transition, and use that time productively. With respect to travelling itself, more than two-thirds of the respondents disagree that 'the only good thing about travelling is arriving at your destination', and nearly half agree that 'getting there is half the fun'” (Mokhtarian and Salomon, 2001:709; there were 1900 respondents).

Within the UK, research for the campaigning organisation Transport 2000 into UK rail considered the potential economic value of rail journeys for business travel if some travel time was productively used (2002). In 2001 nearly 200 million business and personal business trips were made by rail. The study conservatively assumes that: "every rail business traveller on strategic routes undertakes one 
hour of productive work on each business journey - a not unreasonable assumption” (Transport 2000, 2002). Based on this assumption, the value to the economy of this work time, according to the study, would be $£ 731 \mathrm{~m}$ per year. The study did acknowledge the problem of overcrowding (at certain times of day and on certain routes).

\section{A sociological perspective on travelling by car}

It can be easy to presume that unlike the positive ways of using time on a train journey (as set out earlier), the scope for time use for a car journey is substantially reduced, especially in the case of a car driver who must devote attention to the driving task itself. Developing the debates cited earlier of Mokhtarian and Salomon, we now dispel any notion that a journey by car cannot yield inherent benefits for the motorist concerned.

Being in a car is in part being in a place of dwelling or inhabiting, not just of travel and the spending of travel time (see Sheller and Urry, 2000, for the following). Those within a car are able to produce an environment in which a sociability or solitude can occur. Car-drivers control the social mix in their car just like homeowners control those visiting their home. The car is a place to perform business, romance, family, friendship, crime, fantasy and so on. Unlike 'public' transport, the car facilitates a domestic mode of dwelling. The actor-network or hybrid of the 'car-driver' (see Law and Hassard 1999) is surrounded by control systems that simulate the domestic environment, a home from home moving through external environments. The car is a sanctuary, a zone of protection, however slender, between oneself and the surrounding transport environment and between the places of departure and arrival (see Mokhtarian and Salomon, 2001: 702, on 'carcooning').

Central to carcooning is the soundscape of the car, as new technologies of the radio, the cassette player, the CD player and now the TV screen increasingly ensure that this mobile home is filled with sound. The car enables a purer immersion in those sounds, as the voices and the sound of music are there, in the car, travelling right with one as the visual world beyond the windscreen is encountered. Music and voices in the car fills the space. Drivers can co-ordinate the soundscape of the automobile to match their mood or journey. The management of experience through sound technologies is tied to control. Thus some respondents reported their preference for driving alone, so as to more effectively 
appropriate their time. Immersion in sound is enhanced by sole occupancy so as to manage their environment, mood, thoughts, space and the pleasures of travel time (Putnam 2000, reports that 70 percent of American car journeys involve ‘driving alone’).

Moreover, at the beginning of this new century, a further shift is occurring towards the 'intelligent' car. Cars are being hybridised with the converging technologies of the mobile telephone, the personal entertainment system and the computer, so producing new heterogeneous actor-networks.

Some of these features can also be seen in research into 'mobile offices'. Laurier and Philo examine how work activities that were once mainly carried out in offices can now be conducted in company cars functioning as mobile hybrid offices (2001; their study involved only women workers). The car is transformed into an office through its combination with the mobile phone, as well as using the car as a place for files, papers, storage and so on $^{2}$. Work materials can be synchronized and connected to other company members while 'on the road'. The mobile is regularly used to rearrange the day as traffic impedes the smooth planned for series of meetings and encounters, involving a 'playful opportunism'. And even traffic jams can be used to make phone-calls, preparing for subsequent meetings. Team working is achieved by the skilful use of mobile telephony so as to maintain connections both with those back at the office, as well as with others on the road and with whom a 'meeting' might be possible to arrange. Often these face-to-face meetings are held in the many 'thirdspaces' lying along the road network, coffee shops, service stations, cafes, pubs, restaurants and so on.

Thus these mobile workers are each day, driving, listening, communicating, gossiping, scheduling and rescheduling meetings, downloading information, meeting up, moving on, building networks, planning the next meeting and coordinating a complex choreography in time-space. Activities and travelling flow into one another. They are not separate in time or space and therefore we might say they are engaged in complex multi-tasking.

\footnotetext{
${ }^{2}$ While work on the move can and does involve laptops and other communication devices, it is important also to recognise paperwork. Sellen and Harper have documented in detail what they term The Myth of the Paperless Office (2001). They show that in the offices of those working in 'high tech' there is an enduring importance of paper documents. By implication working on and with paper documents will also be important for those working 'on the move', provided of course that the materialities of the mode of transport permit effective and secure working with those pieces of paper.
} 
We have dwelt here on the motorist (and, one might argue, on an elite minority of motorists - an issue we will return to) and in so doing implicitly highlighted some contrasts between travelling alone by car and by public transport. The attraction of the former is that it offers a private space, under the control of the driver. By contrast travel by public transport constitutes being in a public space. Yet the information age is enabling that public space to be privatised by the individual (a simple example in auditory terms, being the Sony Walkman). Meanwhile, travelling by car 'ties up' the hands and (seemingly) the mind of the driver with the driving task, unlike the public transport passenger. However, technological devices are enabling the driver to capitalise on the capacity to multitask and thereby undertake other tasks alongside that of driving (such as the hands-free mobile phone).

\section{TRAVELLING IN THE INFORMATION AGE}

So far, it is clear that ICTs accompany us increasingly on our journeys. However, in many respects the notion of productive travel time use existed a long time before the information age. People were reading books, writing letters and socialising on trains back in the age of steam (see Richards and Mackenzie, 1986). Yet ICTs have grown to play a very significant part in daily lives. Take for example the television. Watching television is a largely passive leisure activity. On average, UK adults devote well over two hours each day to watching television - more than double the amount of time for social life (ONS, 2003). This raises the question of whether people will increasingly watch television while travelling and achieve the same level of satisfaction (Lyons, 2003). Could this substitute for television watching in the home, and, by converting travel time into activity time, facilitate longer and longer journeys being made with more time spent travelling? (Lyons, 2004; many Japanese cars have TV screens that car-drivers as well as passengers can watch!).

Within this section we now explore how the information age is affecting travel and specifically travel time use. We begin from a sociological perspective looking at how information and information exchange has become mobilised. We then consider whether or not the information age might fundamentally be changing how time can be used on the move. Lastly we draw upon the extensive work of Mokhtarian to reflect, in a more holistic way, on the implications of the information age for travel. 


\section{The mobilisation of information}

Knowledge was once physically rooted in specific form (the manuscript, the book, the map), located in particular places (archives, museums and libraries) and embodied within the minds of certain people (scholars, archivists, mapmakers: Brand 1999: chap 12). But knowledge is now transmutating into digitised information (Featherstone 2000). This change can be appreciated through a shifting metaphor of travel, from the stationary, wooden, fixed 'desk' occupied by the individual scholar, to the ephemeral, mobile and interchangeable 'desktop' occupied by anyone (with the right password). With digitisation, information adopts patterns of mobility substantially separate from material presence (Hayles, 1999: 18-20). Information is everywhere (and nowhere), travelling (more or less) instantaneously along the fluid networks of global communications.

As people are on the move, so increasingly the distinction between home and away becomes blurred since people can be said to $d$ well within mobilities. Cars, planes and rail carriages increasingly contain screens, as the provision of computing for those on the move is becoming commonplace amongst airport and train operators. Mobile communications increasingly support 'life on the move' (as at August 200373 per cent of UK adults have a mobile phone: Oftel 2003). Social science research shows the complex patterns of how mobile communications now enable people simultaneously to move, to access information and to communicate with those both far away and significantly those nearby as well (see Peters, 2004; Brown, Green, Harper 2002). Indeed such technologies are increasingly invisible, prostheses, that are taken for granted, ready to hand, part of the background for a mobile, modern, connected life with others. Indeed, this ready-to-handedness of these machines means that even tiny slivers of time can be made 'productive' (Sherry and Salvador, 2002). They provide what Jain explores as the significance of 'equipped waiting' (2003). With such a mobility of information accessible at many places and in various ways, it makes little sense to argue that travelling and undertaking activities are distinct and separate and that an unambiguous value can be placed upon discrete travelling time. 
Are ICT-based uses of time substitutes or enhancements?

The earlier commentary concerning time spent watching television raises the question as to what extent are ICTs providing substitutes for use of travel time and to what extent are they providing enhancements?

The first author recalls with some amusement observing a train passenger using the latest in handheld computer technology. Specifically the passenger was using this touch-screen device to play cards! One interpretation is that the information age in this instance has made no impact - the same passenger 100 years ago could have played the same game but with a real pack of cards. However, an alternative interpretation may render this presumption of substitution less clear. To use a real pack of cards requires a playing surface - something not necessarily available in a crowded train carriage. In contrast the electronic 'substitute' could be played with no such space or even without the need for the passenger to be seated. This suggests that in some instances while 'real' options may disappear from the set of available time uses for a given journey, their ICT-based counterparts will remain. Further, there is also the question of how ICTs change the extent to which the passenger can be equipped for travel time use. A laptop computer, for instance, equips the passenger with enough work to fill a filing cabinet, can hold a multitude of games and could provide electronic reading books. There are other instances where, apparently, ICTs provide enhancements to time use. Without the availability of today's ICTs it would not be possible for people to have their own personalised cinema (portable DVD player) or to be able to speak with people not travelling with them (mobile phone use). However, it remains unclear whether such examples are indeed enhancements or only substitutes. To consider this one needs to look at the attributes of the time uses rather than the time use itself. For example, if watching a film has the primary attribute of relaxation/enjoyment then reading a book might in fact provide equivalent relaxation/enjoyment and hence act as a substitute.

\section{Understanding the relationships between telecommunications and travel}

The preceding discussion section leaves the fundamental question of whether and how ICTs are affecting travel time use (and in turn travel itself) unanswered. 
For many years Mokhtarian and colleagues have sought to shed some light on the relationships between telecommunications and (physical) travel. She suggests that a number of relationships are possible between the two (Mokhtarian, 2003):

- Substitution ${ }^{3}$ (use of telecommunications obviates the need for travel or reduces the amount of travel);

- Complementarity (the "[U]use of one mode of communication can also increase the use of other modes” - this may occur either through enhancement whereby the use of one mode directly causes or facilitates the use of another mode or through efficiency "when the use of one mode is a necessary accompaniment to or side effect of the use of another mode, thereby increasing the efficiency of the latter mode");

- Modification ("sometimes one communication mode modifies something about the use of another mode”); and

- Neutrality ("in some circumstances, use of one mode may leave the use of other modes unaffected”).

Mokhtarian notes that the 'ultimate question' is "not the existence of, say, substitution effects (which certainly do exist), but the net outcome of all the effects we have identified here (i.e. the overall change in demand for each mode).” (2003: 46-47) Presumably this overall change can encompass redistribution of demand in time and space. The focus on overall change emphasises the desire to take full account of all the effects at work rather than to interpret selected effects in isolation. This question does not, however, encompass (fully) the effect of telecommunications on the economic cost of travel (derived notably from how travel time is used).

Taking full account of all the effects at work is non-trivial (as Mackie el al, 2004, have noted in relation to valuation of travel time use by briefcase travellers) and as a result, related empirical evidence remains in short supply. What 'evidence' that does exist must then be interpreted with care. To illustrate this, Mokhtarian takes the example of when transportation and telecommunications uses

\footnotetext{
${ }^{3}$ Substitution here refers to travel as distinct from the reference to substitution earlier which referred to travel time uses.
} 
are observed to increase together. She suggests that there are three fundamental explanations that could be at work (Mokhtarian, 2003):

- observed relationship may be purely spurious;

- $\quad$ each use may be independently correlated with one or more other variables; and

- a genuine uni- or bi-directional causal relationship may exist.

\section{DISCUSSION}

Having presented our hypothesis and the associated considerations and insights, a number of questions stand to be addressed: is the hypothesis in part or in full correct?; to what proportion of the population and travel circumstances does it apply?; what might the behavioural and social implications of the hypothesis, if correct, be?; and what would be the implications for transport appraisal and how should policymakers respond? Additionally, how is the 'information age' changing all of the above?

\section{Extent of validity of the hypothesis}

Anecdotal evidence alone appears to show that at least for some people in some circumstances the hypothesis holds true - for example there are long distance rail commuters who sustain their existence by being able to work, relax or sleep during the journey, something which they believe can only be achieved acceptably by making the journey by train. However, it can be easy to generalise from such selected examples. What about the commuter who stands shoulder to shoulder in a hot carriage wishing they were somewhere else? Or the bus user on a 15-minute journey home laden with shopping?

There are essentially two parts to the hypothesis - the first part claims that people are able to compensate themselves (to some extent at least) for the time invested in the journey; the second part claims that this will affect their travel behaviour. Irrespective of whether the travel time use is judged productive in economic terms, the first part of the hypothesis holds true for an individual who has personally gained some positive (productive) value whether it be through working, playing, socialising, sleeping etc. during the journey. There will clearly be a range of travel time cost 
reductions that can be achieved depending on the individual and the journey. This is illustrated in Figure 1.

Figure 1 indicates that across all individuals and journeys using a given mode of travel, the extent to which travel time is 'productive' (judged as of personal benefit to the individual or alternatively as of benefit economically) will range from counter-productive to 'ultra' productive. Counter-productive travel time represents time use that not only achieves no benefit in itself but also has an adverse effect on time use beyond the journey (e.g. a stressful commute journey affects an individual's level of productivity once they reach work). Unproductive travel time is that where an individual has achieved no benefit - in other words the travel time is wasted time. Productive travel time reflects a use of time that has been of some benefit to the individual. 'Fully' productive travel time indicates that the use of time on the journey has been as beneficial as that time would have been if used otherwise. 'Ultra' productive travel time indicates that the use of time on the journey has been more beneficial than had that time been used otherwise (e.g. getting more work done because of the lack of interruptions which tend to disrupt thinking in the office).

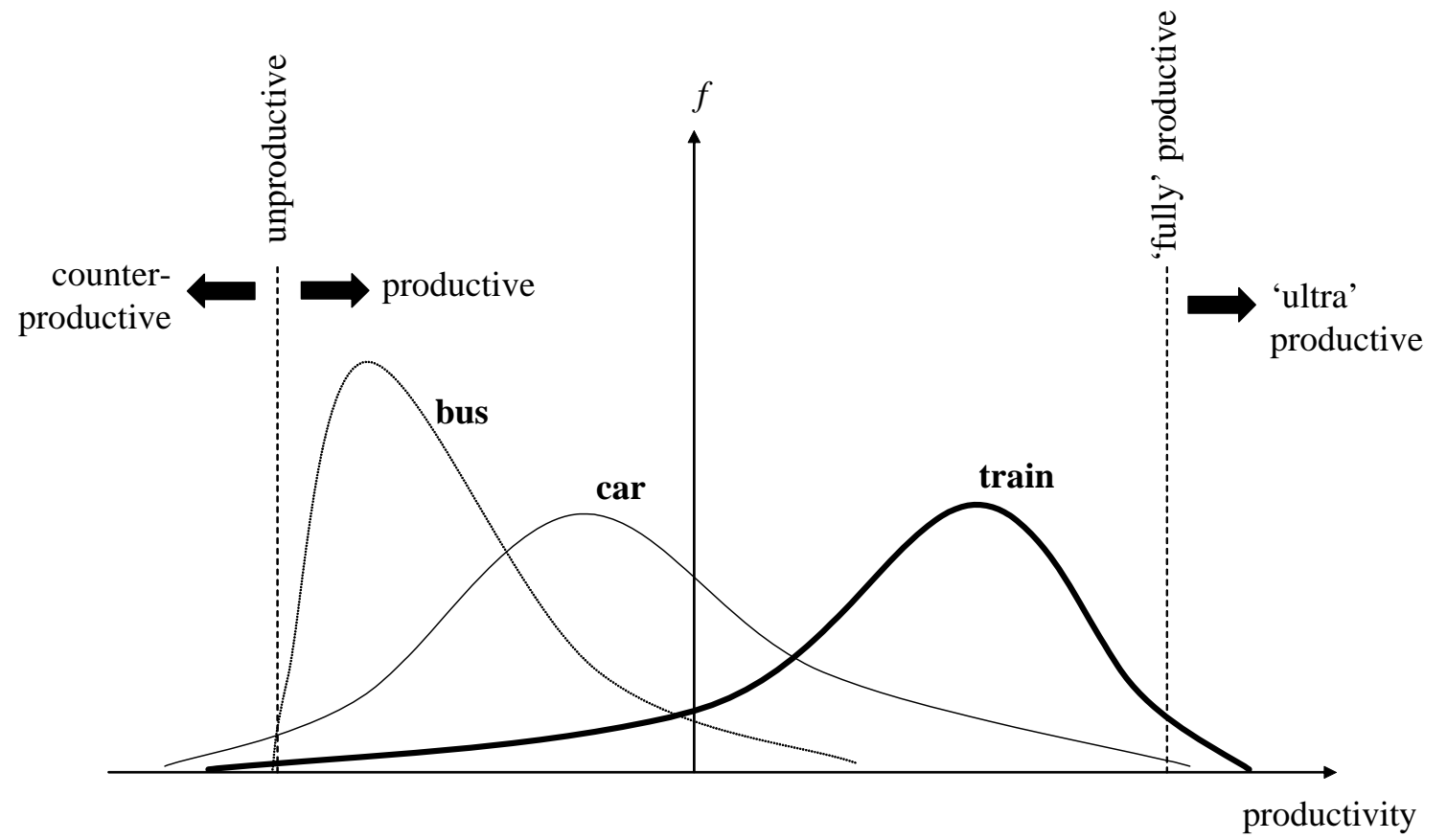

Figure 1: $\quad$ Illustrative frequency distributions of 'productivity' of travel time by mode 
Figure 1 offers a purely illustrative indication of how travel time productivity across all individuals and journeys on a given mode might be distributed. A number of factors will be at work in determining the shape of these distributions. Such factors will relate both to the individuals and to the journeys. Some individuals will be more equipped than others to use their travel time in a worthwhile way. This will relate to how much advance planning they do for their travel time use and hence what they have with them. It may also relate to the range of travel time uses they are able to undertake which in turn could be influenced by their socioeconomic status, state of health or life stage. With regard to the journey, a number of factors can assist or impinge upon the nature and quality of travel time use. These might include: the degree of crowding in the vehicle and the availability of seating; the ride quality; the temperature and level of noise in the vehicle; the degree to which the journey is familiar, reliable and straightforward to negotiate (something relating to both the individual and the journey); and the duration of the journey or stage of journey.

Given so many factors it is impossible to begin to consider how prevalent productive travel time use might be and to produce such productivity distributions in the absence of empirical evidence being available. Accordingly we would advocate that research be undertaken to begin gathering such evidence. Indeed the overarching message we wish to convey in this paper is that in relation to travel time use there are some important questions which remain unanswered which could have significant implications for transport and society. Let us now turn to the second part of the hypothesis, namely that travel time use affects travel behaviour.

The effects on travel behaviour could be direct or indirect. Direct effects are those that influence a given journey such as the commute. These might include a change of departure time, route choice or mode choice or might even lead to a change in the relative location of home and work (i.e. a change in journey distance and/or duration). Indirect effects are those that influence the wider or overall travel behaviour of the individual beyond the given journey for which travel time is being used (for example, a restful or productive long distance commute might increase the propensity for the individual to spend more time travelling for leisure in the evenings and weekends). A clear understanding of the direct and indirect effects is once again dependent upon suitable and sufficient empirical evidence which remains in short supply. We return to the deliberations of Mokhtarian 
(2003) and the complex conundrum of whether or not and if so how behaviour changes become manifest at the aggregate level. That travel time use has existed since travel itself has existed makes the influence of time use on travel behaviour difficult to assess at the aggregate level. Returning to the work of Schwanen and Dijst (2002), Table 2 might suggest that variation of travel time productivity by mode is affecting behaviour. The Table shows that those commuting by train spend twice as much of their overall working day (the time from leaving home to returning home) travelling as those commuting by car. One could infer that this is attributable to a greater opportunity to use 'productively' time on the train than in the car, thereby facilitating longer commutes. However, the difference between train and car might instead be attributable to nothing more than the proximity of compatible job opportunities to individuals' homes and/or the relative speed and affordability of available travel modes. What is also of interest is whether or not any behavioural influences of travel time use (if they exist) are changing or increasing over time - we return to this shortly in relation to the information age.

In relation to behaviour there is also a distinction to be made between: situations where the individual accounts for the opportunity to use travel time in making their journey planning decisions and notably in their choice of travel mode; and situations where travel time use had no bearing on the journey planning decisions, albeit that the individual might then seek to make the best use of the travel time on the chosen mode.

\section{Social implications of the hypothesis}

A myriad of social implications are associated with how travel time is used and we only touch briefly upon such issues here. Social implications will relate both to the individual travel time user as well as to the cumulative consequences for society as a whole. For the individual, they may not change their travel behaviour as a result of travel time use but being able to make more 'productive' use of time may improve their personal wellbeing. Illustrations could include 'restful' travel leading to a refreshed or more attentive participation in activities at work or at home, or social networking by using travel time to converse with friends or colleagues either present on the journey or remote (through use of mobile communications). Cumulative consequences for society as a whole could be 
positive or negative. Travel time use, or more particularly changes therein, could encourage people able to do so to sustain or increase their travel horizons because travelling becomes 'easier'. This could lead to a perpetuation of a society 'on the move' which in turn could exacerbate social inequity between those able to partake in this type of society and those who are not.

However, societal consequences could be positive - people may come to see collective passenger transport more favourably as the mode that offers the best opportunities for productive travel time use. In turn, public transport providers might recognise and nurture this positive attribute of their service such that, additionally, vehicles would come to be seen as points of meeting and social engagements rather than merely 'people movers'. Travel places themselves are increasingly significant places of meeting, the travel is part of the activity. Thus airports are increasingly 'destinations' in their own right (see Jarach 2001, on their multiple services).

Social implications thus become more complex over time. This is something that Geels and Schmit (2000) allude to in their consideration of why many attempts to make future projections on the effects of technology on transport have failed. They point out that there is often an explicit or implicit assumption that the pool of existing social practices remains constant over time in spite of the introduction of a new technology. In the case of travel time use, for example, we might well be misguided to assume that use of that time amounts only to a change in the particular time/place when certain activities in an individual's routine are performed. Travel times, and changes therein, might lead to the set of activities changing or expanding - i.e. there can be significant changes to the pool of social practices.

\section{Implications for appraisal and policymakers}

We have highlighted the importance of travel time in the appraisal of transport schemes. Treatment of travel time, and specifically its assumed value, has a major influence on decisions that affect the development of our transport system. At present, in economic terms, for a given saving in travel time resulting from a proposed transport scheme, the size of the associated monetary benefit depends upon the value of time. Travel time could be productively used to the extent that no time is wasted and hence the monetary benefit of any saved travel time would be zero. In practice any degree of 
productive time use will reduce the monetary benefit whilst the cost of the scheme will remain unaffected. Consequently a scheme that, under the current appraisal framework, showed a benefit-cost ratio of greater than one, might, when taking account of productive travel time use, show a benefitcost ratio of less than one. The result could be that such a scheme is not taken forward.

Taking account of travel time productivity should result in changes in the relative value of time for travel on different modes. To illustrate this and its potential consequences, let us presume for a moment that time can be used more productively on train journeys than on car journeys. This would suggest that the economic value of travel time (VOTT) is lower for train journeys. However, economic VOTT is currently dependent not on the mode per se but on the associated wage rate of the 'average' traveller on that mode. Hence in Table 1 the resource cost per hour of a rail passenger is nearly 50 per cent higher than that for a car driver. (We are here referring to working time.) Were appraisal to take account of productive travel time then this difference in resource cost between the modes would be narrowed and the absolute resource cost for rail lowered. As a consequence a scheme designed to achieve shorter journey times for rail would not yield as much benefit as would currently be the case in UK appraisal.

VOTTs for non-working time reflect people’s willingness to trade time for money. UK appraisal assumes that people "will trade a cheaper, slower journey against a faster, more expensive one” (DfT, 2004). For equity reasons standard VOTT values are used (see Table 1) in appraisal. However, in terms of modelling of travel behaviour, which in itself provides an input to appraisal, VOTT can be varied between individuals. If travel time is used productively then this suggests that the appraisal assumption should change from people trading 'a cheaper, slower journey against a faster, more expensive one' to people trading 'a cheaper less productive journey against a more productive, more expensive one'. The resource cost per unit of non-working time is not mode specific within UK appraisal, but nevertheless the changed assumption could result in a change (downwards) in the standard resource cost values directly affecting appraisal outcomes. The change in assumption could have implications for transport modelling (where VOTT differences between modes are accounted for) and therefore, indirectly, for transport appraisal. 
In considering whether or not transport appraisal should take account of productive travel time use attention should be drawn again to Figure 1. Were it possible to produce empirically-based productivity distributions by mode then this might either reveal that the levels of productive time use across all journeys are insufficient to be accounted for or that the levels are significant and must be accounted for. In the case of the latter it might then be possible to devise a standard set of distributions which would then be embedded within the appraisal calculation process. Once again the issue becomes one of needing empirical evidence.

Implications for policymakers of productive travel time use will depend both on the productivity distributions and on the nature and extent of any resulting behavioural change. Doubtless there are many policy questions that could emerge, for example:

1. Should the working day begin at the start of the journey?

2. Should productive travel time be curbed?

At present in the UK, for the purposes of appraisal at least, commuting is not considered to take place in work time. Yet plainly some people, particularly those travelling by rail, are working during the journey to or from work. Implicitly it may already be that employers and employees are blurring the accepted boundary between the commute and time spent at work. To some degree this would further raise issues concerning appraisal - if the working day begins when one boards the train then it cannot be appropriate in appraisal to class such time as non-work time and reduce its value.

If employers were able to acknowledge formally in certain circumstances that commuting by collective transport enabled equivalent work per unit time to be completed during the journey as would be completed at work, then this could have implications for staff morale and retention and the choice of travel mode.

If we were to subscribe to the belief that ever increasing mobility is undesirable then it might be tempting to suggest that steps should be taken to ensure that travel time cannot be put to productive use, thereby removing any positive utility that could be derived from it. This would restore the attraction of accessing activity centres that are in closer proximity (or which can be reached more quickly). Yet this would seem nonsensical - we surely would not wish consciously to waste time in this way - after all, wasted time cannot be recycled. What might instead be considered is a means to 
discourage the temptation to 'reinvest' travel time that has been converted into activity time in travelling further and for longer periods.

\section{The significance of the information age}

Finally we come again to the question of whether, to what extent and how the information age might be changing the use of travel time. We have already highlighted that it is not the ICTs themselves are important in relation to this question. Rather, it is the change that they might bring about to the types of activity that can be undertaken on the move and more particularly still to the underlying attributes of these activities. In this context there is a need to understand to what extent ICTs provide more than only substitutes to their 'traditional' counterparts and indeed to what extent ICTs used on the move will influence the pool of social practices. Yet again the call for empirical evidence is made - not only do we need to develop the productivity distributions but we need to see how they are changing, or not, over time and determine to what such change is attributable.

\section{CONCLUSION}

This has not been a paper that provides answers. Its contribution is to raise some important new questions (notably in relation to transport appraisal and hence policy) concerning travel and to begin to consider the implications of these questions and how they might be addressed. We have called for the need for much more empirical evidence. For our part we are just embarking on a three-year study in the UK to respond to this call.

Transport studies have evolved. We suggest that we are in the third age of that evolution. The first age was that of infrastructure provision and maintenance - highway design and construction. The second age was that of managing the asset from the first age (i.e. network and traffic management). The third age is that of demand management - understanding our lifestyle needs and determining and influencing how the transport system is best used to support those needs. We believe that travel time use will prove to be a significant consideration in this third age and that the treatment of it in support of policy formulation and evaluation now requires a thoroughgoing reappraisal. 


\section{REFERENCES}

Adams, J. (1999). The Social Implications of Hypermobility. Report for OECD Project on Environmentally Sustainable Transport, Paris.

Brand, S. (1999). The Clock of the Long Now. Phoenix, London.

Brown, B., Green, N., Harper, R. (eds) (2002). Wireless World. London: Springer

Cass, N., Shove, E., Urry, J. (2003). Changing infrastructures, measuring socio-spatial inclusion/exclusion. Sociology Dept, Lancaster University/ Department for Transport, April.

DETR (1998). Guidance on the New Approach to Appraisal. Department for the Environment, Transport and the Regions, September, TSO, London.

DETR (1999). Transport and the Economy. The Standing Advisory Committee on Trunk Road Assessment, October, TSO, London.

DETR (2000a). Transport 2010: The Ten Year Plan - Summary. Department for the Environment, Transport and the Regions, July, TSO, London.

DETR (2000b). Guidance on the Methodology for Multi-Modal Studies. Department for the Environment, Transport and the Regions, May, TSO, London.

DETR (2001a). Transport Trends: 2001 Edition. Department for the Environment, Transport and the Regions, March, TSO, London.

DfT (2004). Values of Time and Operating Costs. TAG Unit 3.5.6, Department for Transport, June.

DTLR (2001). Focus on Personal Travel: 2001 Edition. Department for Transport, Local Government and the Regions, December, TSO, London.

Featherstone, M. (2000). Archiving cultures. British Journal of Sociology, 51: 161-84

Featherstone, M., Thrift, N., Urry, J. (eds) (2004). Cultures of Automobility. Special issue of Theory Culture and Society (forthcoming).

Froud, J., Johal, S., Leaver, A., Williams, K. (2003). Not Enough Money: the Resources and Choices of the Motoring Poor. School of Accounting and Finance, University of Manchester. Unpublished. 
Geels, F.W. and Smit, W.A. (2000). Failed technology futures: pitfalls and lessons from a historical survey. Futures, 32(2000), 867-885.

Hayles, N.K. (1999). How We Became Posthuman. University of Chicago Press, Chicago.

Hensher, D.A. (1977). The Value of Business Travel Time. Pergamon Press, Oxford.

Höjer, M. and Mattsson, L.-G. (2000). Determinism and backcasting in future studies. Futures, 2, 613-634.

Jain, J. (2003). Networks of the Future, Lancaster University PhD Thesis.

Kenyon, S., Lyons, G. and Rafferty, J. (2002). Transport and social exclusion: investigating the possibility of promoting inclusion through virtual mobility. Journal of Transport Geography, 10(3), 207-219.

Laurier, E. and Philo, C. (2001). 'Meet you at junction 17': a socio-technical and spatial study of the mobile office. ESRC Award Final Report (at http://www.geog.gla.ac.uk)

Law, J. and Hassard, J. (1999) (eds) Actor Network Theory and After. Oxford: Blackwell/Sociological Review

Lyons, G. (2003). Future mobility - it’s about time. Universities Transport Study Group Conference. Loughborough, January.

Lyons, G. (2004). Transport and Society. Transport Reviews, 24(4), 485-509.

Mackie, P.J., Wardman, M., Fowkes, A.S., Whelan, G., Nellthorp, J. and Bates, J. (2003). Value of Travel Time Savings in the UK. Report to the Department for Transport, January.

Mokhtarian, P.L. (2003). Telecommunications and Travel - The Case for Complementarity. Journal of Industrial Ecology, 6(2), 43-57.

Mokhtarian, P.L. and Chen, C. (2004). TTB or not TTB, that is the question: a review and analysis of the empirical literature on travel time (and money) budgets. Transportation Research A (forthcoming).

Mokhtarian, P.L. and Salomon, I. (2001). How derived is the demand for travel? Some conceptual and measurement considerations. Transportation Research A, 35, 695-719.

Oftel (2003). Consumers’ use of mobile telephony. Office of Telecommunications, October. 
ONS (2003). Social Trends. No. 33 - 2003 edition, Office for National Statistics, TSO, London.

Pas, E.I. (1996). Recent Advances in Activity-Based Travel Demand Modelling. Proc. Activity-Based Travel Forecasting Conference, USDOT.

Peters, S. (2004). Information Mobility: the behavioural technoscape. Alternative Mobility Futures Conference, Lancaster, January.

Putnam, R. (2000). Bowling Alone. Simon and Schuster, New York.

Rajé, F. (2003). Impacts of Road User Charging/Workplace Parking Levy on Social Inclusion/Exclusion: Gender, Ethnicity and Lifecycle Issues. Oxford: Transport Studies Unit/Dept for Transport.

Richards, J. and Mackenzie, J. (1986). The Railway Station. Oxford University Press, Oxford.

Salomon, I. and Mokhtarian, P.L. (1998). What Happens When Mobility-inclined Market Segments Face Accessibility-enhancing Policies? Transportation Research D, 3(3), 129-140.

Schafer, A. (1998). The Global Demand for Motorized Mobility. Transportation Research A, 32(6), 455-477.

Schafer, A. and Victor, D.G. (2000). The future mobility of world population. Transportation Research A, 34, 171-205.

Schwanen, T. and Dijst, M. (2002). Travel-time ratios for visits to the workplace: the relationship between commuting time and work duration. Transportation Research A, 36, 573-592.

Sellen, A. and Harper, R. (2001). The Myth of the Paperless Office.MIT Press, Cambridge, Mass.

Sheller, M. and Urry, J. (2000). The city and the car, International Journal of Urban and Regional Research. 24: 737-57

Sherry, J. and Salvador, T. (2002). Running and grimacing: the struggle for balance in mobile work, in Brown, B., Green, N., Harper, R. (eds) Wireless World. Springer, London.

Transport 2000 (2002). The Case for Rail. July, Transport 2000.

Urry, J. (2002). Mobility and Proximity. Sociology, 36(2), 255-274.

Wardman, M. and Mackie, P. (1997). A review of the value of time: Evidence from British experience. Proc. European Transport Forum, Transportation Planning Methods I, September, $87-100$. 